Anuario del Instituto de Historia Argentina, vol. 17, n 2, e047, diciembre 2017.

ISSN 2314-257X

Universidad Nacional de La Plata.

Facultad de Humanidades y Ciencias de la Educación.

Centro de Historia Argentina y Americana

\title{
Los Habsburgo en el Río de la Plata: Gobernadores de capa y espada en el Buenos Aires colonial temprano
}

\author{
The Habsburgs in the Rio de la Plata: lay and sword Governors in \\ early colonial Buenos Aires
}

\section{Oscar José Trujillo}

Universidad Nacional de Luján, Argentina | ojtrujillo@gmail.com

\section{PALABRAS CLAVE}

Buenos Aires

Habsburgo

Siglo XVII

Gobernadores

Militarización

\section{KEYWORDS}

Buenos Aires

Habsburgo

XVII century

Governors

Militarization

\section{RESUMEN}

El objeto de este artículo es analizar el proceso de militarización del estilo de gobierno que se percibe en el contexto de la Gobernación del Río de la Plata, desde su creación en 1617 hasta fines del siglo XVII, cuando los Habsburgo dejaban paso a los Borbones. Se proponen como claves de ese proceso la descripción del perfil de esos gobernadores y el análisis de su correspondencia con el Consejo de Indias, comparados con el proceso de dotación y equipamiento militar de la ciudad. Desde los primeros tiempos del poblamiento y organización jurisdiccional del territorio, la cuestión militar fue decisiva a la hora de configurar la geopolítica de la Corona con respecto al espacio local. 


\section{Buenos Aires, de aldea marginal a "llave del reino del Perú"}

“...donde hay muchas puertas, mal se puede defender la entrada...”

Hernandarias, 1616

El despoblamiento de la primera Buenos Aires en 1541 implicó un brusco golpe de timón en el proceso de poblamiento del estuario rioplatense. Abortada la posibilidad de sostener un enclave en el extremo de la cuenca como punto de enlace para los navíos que comunicaran al Paraguay con el Atlántico, la dinámica del poblamiento inicial tuvo como epicentro regional a Asunción, y concentró sus esfuerzos en el interior del litoral por algunas décadas (Guérin, 2000). Luego de ensayar una serie de acciones tendientes a conectar el espacio rioplatense, controlado y referenciado en Asunción, con las costas meridionales del Brasil, esa expansión hacia el interior del continente coincidió con las expediciones castellanas que, desde el Perú, avanzaban hacia el sur. Así, el Tucumán quedaría pronto bajo control peruano, y la competencia con Asunción, volvería los ojos sobre la desembocadura del Río de la Plata, proceso que culminaría con el repoblamiento de Buenos Aires por Juan de Garay, en 1580, y el retorno del interés por la salida al Océano.

A pesar de las presiones que desde muy temprano intentaron oponerse a la consolidación de una salida atlántica de la plata potosina, lo cierto es que Buenos Aires logró sobrevivir y crecer merced al aprovechamiento de algunas pocas permisiones comerciales y muchas otras ilícitas.

Un argumento sería central para defender el sostenimiento de un enclave tan lejano y marginal: la necesidad de proteger un acceso estratégico al corazón mismo del subcontinente (Tarragó, 2016). Justamente sobre ese rol defensivo se articularían discursos que pondrán, desde muy temprano, un énfasis muy claro en la necesidad de dotar y sostener de recursos militares a Buenos Aires. Mucho más cuando, luego de la división de la provincia en 1617, la cabecera de la nueva jurisdicción recayó sobre ella $\underline{1}$. Pero otro peligro se cernía sobre el precario asentamiento y su región: la presencia de distintos focos de resistencia indígena, entre los que se encontraba el de los belicosos guaycurúes, responsables del despoblamiento de Concepción del Bermejo (Pozzaglio y Svriz Wucherer, 2016), o el de los pampas, mucho más cercanos a Buenos Aires (Boccara, 2002).

En palabras de Hernando Arias de Saavedra, el último gobernador de la extensa jurisdicción que unía a Asunción con Buenos Aires, era imprescindible resolver lo desprovisto y falto de armas y municiones que estaba el puerto. Su temor era que los enemigos se percataran de la comodidad de Buenos Aires como escala antes de cruzar el Estrecho, y de la facilidad que tendrían para internarse desde allí hacia el interior: "pues donde hay muchas puertas, mal puede defenderse la entrada”. Para ello, proponía instalar una atalaya en las islas de San Gabriel que sirviese para advertir sobre la presencia de navíos enemigos, así como para reforzar las defensas de la ciudad-puerto: "la verdadera defensa y guarda de este puerto principalmente consiste en presidio y fuerza de gente pagada”, al mismo tiempo que advertía que “el fuerte de esta ciudad no tiene más que el nombre porque como los materiales no son a propósito, está arruinado y caído lo que edificó Don Diego Marín Negrón, mi antecesor”르. 
Así, desde la misma división de la provincia del Río de la Plata, Buenos Aires pasaría a ser no sólo una marca de posesión efectiva en la frontera austral, sino también a ser apreciada por la Corona como un enclave militar. Y es esa visión la que sirvió no sólo para dotar a Buenos Aires de una temprana presencia militar, sino también para orientar la elección de los representantes del poder regio en el territorio.

\section{"Gobernadores de capa y espada": el perfil de los gobernadores de Buenos Aires}

Los gobernadores fueron, sin duda, de las figuras más importantes del complejo andamiaje político del gobierno de la monarquía hispánica en América. Más numerosos que los virreyes, su misión fue hacer visible la autoridad monárquica en los más remotos confines del territorio (Trujillo, 2014).

Más allá de la multiplicidad de funciones que se incluían en la comisión que los designaba, y que incluía funciones de gobierno, justicia, guerra y fiscalidad, las atribuciones militares parecen haber sido determinantes en la elección de los hombres que ocuparon el cargo en Buenos Aires. Y, si bien la gran mayoría de los gobernadores seleccionados por el Consejo de Indias y designados por voluntad del rey, fueron militares de carrera y experiencia demostrada, es interesante ver que también los que ejercieron de manera interina el cargo -fuera como lugartenientes de un gobernador fallecido, por nombramiento del virrey o de la Real Audiencia de Charcas- respetaban el mismo perfil: sólo uno de ellos careció de cargo militar, el oidor Alonso Pérez de Salazar, que apenas cubrió el puesto por un encargo transitorio del virrey -ocurrido por la muerte del gobernador Góngora-, quien aprovechó la presencia de Pérez de Salazar en Córdoba en ocasión de la instalación de la Aduana Seca, en 1623 (ver Tabla 1)

Un caso ciertamente extraordinario fue el de Manuel de Prado Maldonado. Luego de abortarse la asunción del sucesor de Agustín de Robles fue designado desde el Consejo de Indias como el único gobernador de la lista que no tenía grado militar. Muy poco tiempo después, por consulta de la Junta de Guerra, que advirtió esa carencia en el gobernador, el rey revocó la designación, despachó a Maldonado al Corregimiento de Oruro, y nombró al maestre de campo Alonso Juan de Valdéz Inclán en su reemplazo. (Molina, 2000). 
Tabla 1. Gobernadores de Buenos Aires entre 1617 y 1700

\begin{tabular}{|c|c|c|c|c|}
\hline Gobemador & Posesión & Designsoión & Mlitar & Dorden \\
\hline D iego de Góngora & $17 / 11 / 1618$ & RealCédula & Capitán & Caballe ro de Santiago \\
\hline D iego P áez de Clavijo (Interino) & $21,05 / 1623$ & Teniente General de Góngora & Sargento Mayor & \\
\hline Alors o Pérez de Salazar(Inter ino) & $30,09 / 1623$ & RealProuisión del Virrey & Didorde Charcas & \\
\hline Francis co De Céspedes & $19,09 / 1624$ & RealCédula & Capitán & \\
\hline Pedro Esteb an Dávila & $26 / 12 / 1631$ & RealCédula & Maeste de Campo & Caballero de Santiago \\
\hline Mendo de la Cueva y Benavídez & $29 / 11 / 1637$ & RealCédula & Maeste de Campo & Caballero de Santiago \\
\hline Francis co de Avend año yvaldwivi a inter ino) & $08 / 11 / 1640$ & Prouisión de la RealAudiencia & Maeste de Campo & Caballero de Santiago \\
\hline Ventura Moxica & $13 / 12 / 1640$ & RealCédula & Capitán & Caballero de Santiago \\
\hline Pedro Rojas yAcevedo (interino) & $0901 / 1641$ & Teniente General de Moxica & General & \\
\hline Andrés de Sandoval(interino) & $1707 / 1641$ & Provisión de la Real Audiencia & Marino retirado & \\
\hline Jerónimo Luis de Cabrera (interino) & $29 / 10 / 1641$ & Real Prouisión del Virrey & General & Rech aza do en 1652 \\
\hline Jacinto de Láriz & 09061646 & RealCédula & Maeste de Campo & Caballero de santiago \\
\hline Pedro Baigorri Ruiz & $19.02 / 1653$ & RealCédula & Waestre de Campo & Caballero de Santiago \\
\hline Alors o Mercado y Villacorta & $26.05 / 1600$ & RealCédula & Capitán & Caballero de Santiago \\
\hline José Martínezde Salazar & $28,07 / 1663$ & RealCédula & Waestre de Campo & Caballero de Santiago \\
\hline Andrés de Robles & $24,03 / 1674$ & RealCédula & Waestre de Campo & Caballero de Santiago \\
\hline José de Garro (interino) & $27,07 / 1678$ & RealProvisión del Virrey & Waeste de Campo & Caballero de Santiago \\
\hline José de Herrera y Sotomayor(interino) & $19,02 / 1682$ & Teniente Militar de Garro & Capitán de Caballos & Caballero de Santiago \\
\hline Aguztín de Robles yLorenzana & 06,041691 & Realc édula & Sargento General & Caballero de Santiago \\
\hline Manuel de Prado yMaldonado & $05,02 / 1700$ & RealD ecreto & & \\
\hline
\end{tabular}

Los méritos militares propios (Lejonagoitia, 2014), plasmados en las cartas de recomendación y certificación de servicios de los superiores -sumados a los sacrificios y valor de antepasados y parientes directos que contaban como propios-, se montaban sobre una red de influencias y corruptelas que en la Corte tenían un peso decisivo en la conformación de las ternas de favoritos que se presentaban al monarca (Zorraquín Becú, 1973). En el período estudiado, sólo registramos un caso de alguien seleccionado en respuesta a un beneficio -un donativo gracioso que el aspirante podía realizar al momento de presentar sus pretensiones y que disimulaba lo que hubiera sido la adquisición directa del cargo-. Es el caso del maestre de campo Juan de Velazco y Tejada, quien presentó una queja porque, habiendo sido designado -luego de un donativo de 3.000 ducados al rey- como sucesor de Agustín de Robles, su mandato fue anulado para embarcar como gobernador a Manuel de Prado Maldonado, un destacado mercader y miembro del Ayuntamiento de Sevilla (Torre Revello, 1939). Esto parece demostrar que fue a fines de la dinastía de los Austria que empezaron a hacerse más frecuentes los beneficios, seguramente como consecuencia del creciente interés que producía una plaza que tenía cada vez más relevancia mercantil (Sanz Tapia, 2005).

Pero no se trataba sólo de soldados experimentados, sino también de selectos miembros de la oficialidad, la mayoría de ellos distinguidos como Caballeros de la Orden de Santiago. Ese alto porcentaje de miembros de la Orden demuestra la efectiva estrategia de ascenso social que tenía pertenecer a esa selecta élite para los oficiales españoles, quienes iniciaban los tortuosos $-\mathrm{y}$ seguramente onerosos- trámites de aceptación como requisito previo a la solicitud de premios y mercedes que podían culminar con el cargo de gobernador de Buenos Aires, entre tantos otros (Álvarez-Coca González, 1993).

Los frentes de batalla europeos parecen haber sido una cantera muy fructífera para el reclutamiento de estos gobernadores. Flandes fue uno de esos escenarios.

Diego de Góngora había combatido allí con tropa a su cargo en 1602, y había participado en 
numerosos hechos de armas "como lo hizo en el sitio y toma de Ostende, donde fue nombrado para ganar, defender y reconocer puestos y cegar fosos”. También había estado en la voladura del fuerte de Omón y en la toma de un reducto denominado Puercoespín, por el particular diseño que permitía defenderlo desde todas direcciones (Batista González, 2007): “y cuando se voló la primera mina de él, fue nombrado para defender aquel puesto. Y la noche que se ganó la fortificación llamada puercoespín, que fue de las más considerables de aquel sitio y se peleó con la porfía que se sabe, se halló en ganarle”․․ Pedro Esteban Dávila, Mendo de la Cueva, Ventura Moxica, Jacinto de Lariz, Pedro Baigorri, José de Garro, José de Herrera y Agustín de Robles relataron en sus relaciones de mérito que habían servido allí.

Por Francia pasaron Mendo de la Cueva, José Martínez de Salazar y José de Herrera. Los recorridos bélicos incluyeron también Alemania, Italia y Portugal, aunque también las Azores, Cabo Verde y Marruecos fueron territorios que vieron pasar a varios de estos militares. En el propio territorio español, las plazas de Cataluña, Galicia, Extremadura y Cantabria también fueron parte de la carrera anterior al destino rioplatense de varios de ellos.

Los frentes americanos también sirvieron para engrosar la carrera y los antecedentes de los futuros gobernadores de Buenos Aires. Así, la experiencia en la guerra contra los araucanos fue la plataforma de despegue de Diego Páez de Clavijo y Francisco de Avendaño, del mismo modo que el combate a los belicosos calchaquíes impulsó la carrera de Jerónimo Luis de Cabrera y Alonso Mercado. Otras plazas, como Yucatán, Portobelo y Pernambuco también los vieron pasar en su carrera de ascenso.

En esas relaciones de méritos se relataban bizarras anécdotas con el objeto de justificar la justicia de una merecida merced. Páez de Clavijo, hacia 1616, declaraba que siempre “acudió con mucho cuidado, puntualidad y diligencia, muy a satisfacción de sus mayores, sustentando armas, caballos y criados”, combatiendo en numerosas malocas y entradas contra los araucanos ${ }^{4}$. Más elocuente fue el relato de un superior de Mendo de la Cueva, quien narraba que en Flandes éste "peleó con mucho valor hasta llegar a las manos, como también lo hizo cuando el enemigo acometió al dique del Conde de Buco, y recuperó una cañonera que el enemigo tenía ganada”. En otra ocasión, según el mismo documento, "llevando consigo cincuenta y seis infantes y nueve caballos en convoy, encontró con el enemigo y peleó con él, y pasó a su comisión degollando a nueve o diez soldados y cumplió con su despacho"포.

En un desembarco en Marruecos, Andrés de Sandoval certificaba haber sido "uno de los primeros que saltaron a tierra”, así como haber servido siempre con particular cuidado y puntualidad, siendo considerado por sus superiores como "benemérito de la merced que Su Majestad fuere servido hacerle" $\underline{\underline{6}}$.

En 1670, los méritos del capitán Mercado y Villacorta resumían los treinta años de servicio con escalas en Cataluña y Perú. En Lérida, cuando se encontraba en misión de reconocimiento con su compañía, "dio en dicha emboscada del enemigo, y peleando con él fue herido de una estocada en la cabeza y hecho prisionero y llevado a Barcelona donde estuvo un año pidiendo limosna en la cárcel pública, hasta ser canjeado”. Libre de su cautiverio, volvió a las trincheras del frente donde sufrió otras heridas, “pero desbaratando la infantería, degollando y haciendo muchos enemigos”, y 
siempre logrando el reconocimiento de sus superiores, que "aprueban el mucho valor, satisfacción, crédito, experiencia y puntualidad" del oficial ${ }^{7}$.

Andrés de Robles también se vanagloriaba de sus heridas. En Extremadura había sido alcanzado por un pistoletazo, y más tarde herido en un muslo de un arcabuzazo. Y aunque luego se recuperó de otro disparo en la ingle, le mataron al caballo de un cañonazo y salvó milagrosamente su vida cuando su casco lo protegió de un par de cuchilladas $\stackrel{8}{\text {. }}$

La elección de militares de carrera y experiencia se constituyó, entonces, en una constante desde la más temprana historia del poblamiento rioplatense. Pero no faltaron detractores. El más firme de ellos fue el oidor de Charcas Andrés de León Garabito.

Presente en Buenos Aires en 1631 como visitador de las Reales Cajas porteñas, se encargó de descalificar las decisiones del Gobernador Pedro Esteban Dávila, afirmando, por ejemplo, que eran superfluos los gastos que pretendía hacer en el Presidio. Pero más allá de ese cuestionamiento tan puntual, el funcionario se encargaba de cuestionar la elección de militares para el cargo, señalando que "es necesario quitar esta mano a los gobernadores, que con no tenerla por Real Cédula y ordenanzas en la hacienda se administra con muy poca limpieza y los oficiales reales no tienen (por la opresión que padecen) el uso libre de ella”. Su proyecto incluía la creación de una audiencia que vigilara esos excesos con un presidente que no fuera jefe militar: "sería de parecer gobernase esta provincia persona de letras con autoridad de oidor”. El poder militar de los máximos representantes de la Corona en el Río de la Plata, para Garabito, explicaba la “esclavitud y opresión” que sufrían los “miserables vecinos” de Buenos Aires: "Por la mano que tienen para inclinar al pueblo a su voluntad que siguen por temor del daño que les puede venir”. Un temor fundado en "la desigualdad que hay de súbditos a superior” y en la distancia que aumentaba la opresión y la tiranía $\underline{\text {. }}$.

Treinta años después fueron los jueces oficiales de la Real Hacienda los que denunciaban el excesivo poder de los gobernadores, quienes se quejaban de que, amparados por la fuerza militar de 600 infantes “a orden y voluntad expresa de su Gobernador y capitán General que rondan playas y caminos de mar y tierra (...) por cuya causa nosotros no podemos ni osamos salir a rondar (...) temiendo el embarazo y competencias (...) es dueño tan absoluto de los embarcaderos”프.

Más allá de las críticas y las denuncias, la Corona nunca desvió su estrategia. Incluso cuando se creó una audiencia, su presidencia fue encomendada a dos destacados militares, Mercado y Villacorta -quien no llegó a desempeñarlo-, y José Martínez de Salazar, su primer y único presidente. En la breve experiencia de la audiencia que se creó, de tipo pretorial, vemos la intención de reforzar ese estilo militar de gobierno $\underline{11}$, no sólo elevando la jerarquía administrativa de Buenos Aires, sino concentrando, además, funciones en el gobernador-presidente, un hombre de “capa y espada” (Levaggi, 1982).

La selección y provisión de estos cargos demuestra el carácter estratégico que para el gobierno de las Indias tenía el estuario rioplatense. En el reclutamiento de los hombres que ocuparon la gobernación se reflejó claramente el interés de protegerse de los riesgos que, tanto desde el exterior como del interior del territorio, acechaban a la soberanía castellana en el sur del continente. Se trató así de un proceso que fue consolidando un estilo de gobierno de neto corte militar, aun cuando su 
correlato concreto -la dotación de hombres, recursos e infraestructura- viviera vaivenes, interrupciones y retrocesos. Para resumir la importancia de estos funcionarios y de su rol como garantes de la presencia hispánica, una definición de Jean-Pierre Dedieu: "Si en algún sector se expresa una política de gobierno de parte de la monarquía, es allí” (Dedieu, 1998).

\section{Un fuerte para Buenos Aires}

Además de la elección de militares de carrera, méritos probados y prestigio para la designación de los titulares de la gobernación, la decisión estratégica de militarizar desde temprano el espacio rioplatense debía tener una expresión material más concreta: la dotación de una plaza fortificada, primero, y la inmediata presencia de tropa permanente, después.

Desde fines del siglo XVI se registraron los primeros antecedentes relacionados a la fortificación del puerto de Buenos Aires. A las recomendaciones del gobernador Ramírez de Velazco de 1592 al Consejo de Indias, sobre la necesidad de erigir un fuerte allí, el Consejo no emitió respuesta. La iniciativa empezó a concretarse por mano de un gobernador interino, Hernando de Zárate, quien entre 1594 y 1595 dio inicio a las obras, movido por la urgencia de noticias de corsarios que acechaban el Río de la Plata, obra para la que empleó los escasos -y muchas veces criticados por inútiles- materiales locales y mano de obra indígena (Gandía, 1939)

La Real Fortaleza de Don Juan Baltasar de Austria tenía más lustre en su nombre que en su realidad material: un piso de tierra apisonada, un cerco incompleto construido con la tierra de un foso que rodeaba parte de la estructura, custodiado por apenas ocho piezas de artillería de corto alcance (Birocco, 2015)

Desde entonces, la atención del Consejo de Indias pasó a registrar la importancia militar de la pequeña aldea. Varias consultas tratadas en ese cuerpo dan cuenta de decisiones tales como las de presupuestar el envío de tropas, artillería y municiones, así como las del nombramiento de un ingeniero y un castellano para el nuevo establecimiento militar $\underline{\underline{12}}$.

Pocos años después, en 1599, el gobernador Valdez y de la Banda denunciaba que la construcción ya estaba reducida a un corral de tapias, y los cañones, hundidos en la tierra. Aunque prosiguió las obras de construcción -amplió la Casa del Gobernador y unos depósitos-, su sucesor, Hernando Arias de Saavedra, debió continuarlas agregando un mirador e instalaciones para la Aduana $\frac{13}{}$.

Desde temprano, luego de reconocer las dificultades defensivas que presentaba el terreno, surgió la necesidad de crear fortificaciones que complementaran e hicieran más efectiva la capacidad militar de resistir una posible invasión. En 1599, Valdez y de la Banda escribía a la Corona proponiendo la creación de otro fuerte, en el Riachuelo:

La artillería del fuerte no alcanza al Riachuelo de puntería, ni al lugar donde dan fondo los navíos, ni se puede poner cerca de él porque todo es anegadizo y pantanoso. Con todo estoy resuelto de hacer sobre el Riachuelo una estacada de madera y de alguna piedra del lastre de los navíos, y encima tierra en que poner un par de piezas de artillería para defender aquel Riachuelo que será de grandísima consideración porque no entrando en el Riachuelo no pueden estar cuatro días que no corran con gran peligro de perderse (Gandía, 1939). 
En 1609, el gobernador Negrón reiteraba la imagen lastimosa que siguió repitiéndose a lo largo del siglo: las quejas por la deplorable situación de la construcción y la necesidad imperiosa de obras de refacción, ampliación y equipamiento. Un argumento que los testimonios y evidencias reiteradas confirman, pero que muchas veces disimulaba la intención de los gobernadores de meter mano en las Cajas Reales para emprender costosas obras $\frac{14}{\text { : }}$ "El fuerte está muy falto de reparos, porque como la cerca es de tapias, con el tiempo y las aguas se han caído muchas”, por lo que urgía “reedificar el dicho fuerte y reparar la dicha casa del gobernador”쓰.

En un nuevo mandato de Hernandarias, el gobernador se valió de mano de obra indígena y de unos negros depositados en el puerto para continuarlas. Al momento de hacerse efectiva la división de la provincia en 1618, el fuerte ya tenía completo su perímetro con terraplenes y baluartes, empleando para la finalización de las obras, algunas rocas traídas de la Isla Martín García y maderas de las Misiones. De esta época data el texto anónimo que un portugués escribió presentando con lujo de detalles las condiciones defensivas de distintos puntos del Virreinato del Perú, y que destacaba la fragilidad defensiva de Buenos Aires:

La ciudad no tiene ninguna fuerza. Está puesta y edificada a la orilla del mismo río, y los navíos que a ella vienen se quedan sin llegar a la orilla, a un tiro de mosquete, y pueden echar ancla, que el río corre muy manso y apacible. Las casas del gobernador casi que bate el agua en ellas. Esta casa tiene un pequeño torreón que está frontero con el río y en él están cuatro pequeños cañones de batir, y no hay parte donde tenga otra ninguna defensa. Para querer entrar a la ciudad, por cualquiera parte del río pueden echar gente en tierra en barcos o lanchas, porque el río corre muy manso por todas partes y no tiene bosque ni monte, toda es tierra llana (Lewin, 1958).

Góngora, primer gobernador después de la división de la Provincia, comenzaba su gestión observando el peligro defensivo en que se encontraba Buenos Aires por la inmensidad del territorio circundante: "por ser desierto e inhabitado y su costa extendida más de 20 leguas, sin armas suficientes para su defensa”. El gobernador no dejaba de señalar la importancia estratégica de la ciudad: "por ser socorro y llave de estos reinos del Perú y por dónde con más brevedad podrán llegar las nuevas de enemigos que corren estos mares a los virreyes y gobernadores de Chile”. Muy a su pesar, y aun habiendo concluido la reparación de las casas reales, éstas apenas merecían llamarse fuerte $\underline{\underline{16}}$. A esta crítica situación había que sumar la fragilidad de la frontera interior. La belicosidad de los guaycurúes ponía en riesgo no sólo la deseada evangelización de esas comunidades, sino también la misma existencia de los vulnerables asentamientos españoles. Para el recién asumido funcionario, la solución al peligro radicaba tanto en la presencia efectiva de fuerzas militares, como en una política que les diera doctrina "con suavidad y buenos medios", sin declararles abiertamente la guerra, pues esto sólo perjudicaría a los propios vecinos "quedando éstos y los que habitan estas provincias sin gente de servicio" 17 .

Las mismas preocupaciones se reflejaban en las Reales Cédulas que llegaban desde la península: Por un lado, se le exigía a Góngora evaluar el pedido del procurador de Asunción de llevar "guerra a fuego y sangre a los Guaycurús y Payaguas”, por ser "materia tan grave”. En otra Real Cédula se le advertía "que holandeses y otros corsarios trataban de invadir estas costas", para lo que se le 
solicitó evaluar la posibilidad de fortificar la Isla de Maldonado. La respuesta no podía ser más penosa: “con todo secreto”, Góngora resumía su “dificultosa defensa y falta de armas, municiones y gente (...) es tan grande que no puede hacer fortificación en ningún lado, ni en la isla de Maldonado, ni en el puerto de Montevideo ni en las islas de San Gabriel, ni en otra parte” $\underline{18}$.

Después de dos interinatos, en septiembre de 1624 asumía el gobernador Francisco de Céspedes. También él observaba la indefensión de Buenos Aires, pero agravada por una crítica coyuntura: la caída de Bahía en mano de los holandeses en junio de ese mismo año $\underline{19}$. Apenas llegado a destino, el nuevo gobernador hizo junta de guerra, alistó "gente, armas y municiones”, y observó el lamentable estado de las casas reales y, especialmente, de "lo que llaman Fuerte”. Del mismo modo, y hasta con las mismas palabras que sus antecesores, aprovechaba la misiva para pedir urgentes socorros en materiales y unos 300 soldados $\underline{20}$. En otra carta del mismo día, Céspedes insistía en la poca defensa del puerto, "así de gente como de armas y municiones”, vaticinando un desastre si Buenos Aires cayese en manos enemigas: "si por nuestros pecados sucediese, le corren las provincias de Tucumán, Paraguay y Reino del Perú”, pero también advertía de otro peligro: “se me ocurre otro daño mayor, que es poder los enemigos tomar el puerto de Montevideo", por lo dilatada de su campaña, y por la presencia de indios enemigos que los ayudarían. La solución era disponer de "gente pagada” en el fuerte de Buenos Aires y "hacer población en Montevideo" 21. Dos años después, la presencia de un navío holandés en el estuario volvió a encender la alarma de Céspedes, que volvió a pedir 300 hombres, “alguna artillería y dos galeotas de quince bancos por banda”⒉

Fue con el gobernador Pedro Esteban Dávila que el fuerte comenzó a tener existencia real, dotado de tropa y de su primer escalafón. A este gobernador lo acompañó desde España el primer contingente de tropa veterana, en 1631. Experimentado militar con más de tres décadas de carrera y la jerarquía de maestre de campo, bautizó al fuerte como San Baltasar de Austria, en homenaje al aún príncipe de Asturias (Martínez Casado, 2002). El propio gobernador debió oficiar de ingeniero, “por no haber llegado, aprovechándose de su talento y experiencia”르.

A pesar de ello, las condiciones materiales del emplazamiento siguieron siendo deficientes, $\mathrm{y}$ recurrentes las menciones en la correspondencia de los gobernadores sobre las necesidades imperiosas de resolver su reacondicionamiento, así como la urgencia permanente de dotación de hombres, armas, municiones y demás provisiones.

La Corona debió resolver, por lo tanto, la confirmada necesidad de mantener un enclave de naturaleza militar en un rincón fronterizo y desprotegido de sus dominios atlánticos. Una necesidad que contrastaba de plano con la propia incapacidad económica local para sostener los enormes costos que una presencia militar permanente implicaba, sin ceder a los constantes reclamos de apertura comercial que los vecinos peticionaban desde el siglo anterior.

Para ello, se utilizó un sistema de subsidios, los llamados situados, que al inyectar una periódica suma de metálico desde las Reales Cajas del Potosí con destino al pago de los sueldos militares, daban un cierto respiro a la economía bonaerense (Gelman, 2012). Una solución que sirvió no sólo para el caso porteño -pues se aplicó con éxito en distintos espacios regionales- y que permitió que los costos defensivos de las colonias, y hasta los administrativos, fueran sostenidos por la propia 
economía indiana (Birocco, 2015)

En 1638, Mendo de la Cueva y Benavídez daba cuenta de no haber encontrado pólvora ni artillería en condiciones, pero, merced a su esfuerzo, anunciaba haber socorrido con caballos al reino de Chile, complicado entonces por el recrudecimiento de la guerra con los indios $\underline{24}$. La noticia de la rebelión de Portugal fue una señal de alarma que no hizo más que aumentar un interés geopolítico preexistente por parte de las autoridades metropolitanas con respecto al Río de la Plata como frontera de riesgo. Aun así, en palabras del Gobernador Baigorri: “desde el alzamiento de Portugal, se ha puesto en la mira a los enemigos rebelados, desobedientes a vuestra majestad, fortificando el puerto, más de palabra que de obra”. Desde las reparaciones y ampliaciones de Dávila, la estrategia defensiva se redujo a una sucesión de refacciones, y descansaba en que "el río defiende este puerto de cualquiera mal intento, pues puso Dios un grande y hermoso foso que ciñe la tierra y la divide de un grande banco de arena (...) nunca pasa bajel alguno” 25 . Dos frentes internos concitaban la atención de las autoridades a mediados del siglo. Por un lado, las guerras de los valles Calchaquíes, hacia donde se destinaron esfuerzos de todo tipo en pos de reprimir los reiterados levantamientos. Por otro, la constante vigilancia y frustrados intentos de expulsión de los portugueses de los enclaves portuarios y la necesidad de tomar recaudos frente a las amenazas siempre presentes de un desembarco enemigo (Trujillo, 2009).

El esquema defensivo viviría un renovado impulso con la llegada al Río de la Plata del gobernador José Martínez de Salazar. El nuevo gobernador venía investido, además, como presidente de la recientemente creada Audiencia de Buenos Aires, cuya finalidad era establecer un control judicial y administrativo de mayor rango en la cabecera de la provincia, aunque siempre se respetara lo que sería una constante en la provisión de los cargos de gobernador para Buenos Aires: el perfil militar y la experiencia en batalla de los elegidos.

\section{Táctica y estrategia: El discurso militar y político del gobernador Salazar}

La designación de José Martínez de Salazar marcó un punto cúlmine en la política de los Habsburgo en relación con el Río de la Plata. Aunque la posibilidad de crear una audiencia venía siendo pedida desde Buenos Aires y analizada en el Consejo de Indias desde muchos años atrás, la designación del nuevo gobernador coincidió con el establecimiento de un máximo tribunal en el puerto. Entre sus objetivos, además del de acercar la administración de justicia a los súbditos del alejado puerto, se manifestó desde un principio la necesidad de frenar los abusos que se cometían. El gobernador Salazar, su primer presidente, resumía así los tres motivos por los que se había creado:

...uno el aumento y opulencia de ella, otro para que tuviesen los vasallos de estas provincias, vecinos, la administración de justicia más inmediata por la gran distancia de la de los Charcas y tercero obviar y remediar los excesos en las arribadas maliciosas $\underline{26}$.

Pero la nueva jurisdicción quedaba presidida por un militar $\underline{27}$, no por un letrado. El nuevo presidente y gobernador, era maestre de campo y caballero de la Orden de Santiago, dos características comunes en la mayoría de los gobernadores designados por la Corona. Había peleado en la guerra contra Portugal, destacándose en la defensa del puente de Lérida, y había participado de 
la administración de Puebla de Sanabria y en el Castillo de San Luis Gonzaga, siempre en la frontera con Portugal (Molina, 2000).

Al finalizar su mandato en 1672, Salazar presentó un escrito que tituló: "Discurso militar y político sobre la mejor defensa del Puerto de Buenos Aires, aumento de sus habitadores y conservación de las Provincias del Río de la Plata, Tucumán y Paraguay”로․

Allí, alardeando de sus 43 años de servicio continuos en las armadas y ejércitos de Su Majestad, Salazar resumía una serie de “apuntamientos”, inspirados además en sus conocimientos de "las matemáticas, con más práctica que teórica en las fortificaciones”. Su intención era que fueran analizados por la Junta de Guerra del Consejo y por su sucesor, cosa que efectivamente se concretó.

Del mismo modo que los gobernadores anteriores, su primer mirada sobre la situación de Buenos Aires fue la indefensión en que la encontró en momento de su llegada, "por no haber en él, puesto alguno fortificado, pues el que llaman Fuerte, sólo lo era en el nombre y en el dibujo de un papel iluminado".

El primero de sus apuntamientos se refería a la dotación de hombres para la plaza. Los 300 que se verificaban, debían ser elevados a 500, en cuatro compañías de 125 soldados: "las dos sirvan a caballo armadas cada una con cincuenta lanzas y adargas, cuarenta mosquetes y treinta y cinco arcabuces, a la manera y en la forma de Dragones”. Su propuesta preveía que, en costas tan dilatadas, si hubiera "caso de enemigos”, pudiera agrupar esas compañías y movilizarlas con celeridad para impedir desembarcos o, en su defecto, para desmontar y escuadronarse. Las otras dos compañías propuestas debían armarse de mosquetes, arcabuces y partesanas. Y a esa infantería, "se agreguen las compañía del número de la ciudad, armándola el Gobernador de arcabuces y partesanas".

Sobre la tropa local, su visión no fue muy positiva. En primer lugar, por ser "poca y de mala calidad”, y luego porque por tratarse de vecinos de las chacras y estancias, sólo deberían armarse de lanzas y adargas, por ser las armas "que más se aplican y de mayor efecto para esta tierra”, pero que se formen en batallones separados a las dos compañías de a caballo "para que no se huyan y guarden la disciplina”. Por ser "prácticos en las Pampas” quería destinarlos a recorrer caminos, pajonales y pantanos, antes que al combate en caso de desembarco, por "la flaca resistencia que los habitadores de estas tierras hacen a los enemigos del Norte”, tal como pudo verse, según su juicio, en Portobelo y Panamá en 1667 y 1670.

A continuación, una clave del proyecto militar de Salazar: Propuso crear un "fuerte real" en el paraje “que llaman del Río Luján”, a unas diez leguas del puerto, obra que inició pero que nunca se concluyó (Chiri, 1973). Si con los 500 hombres de la dotación sumados a la gente de la tierra no fuera posible defender la ciudad, la tropa podría encontrar en ese fuerte una segura retirada. Además, el sitio sería ideal para cortar las comunicaciones entre los invasores y el interior, a la vez que servir para reunir las fuerzas de la campaña y los refuerzos de las provincias del interior para la reconquista. Otro objetivo era evitar que los indios enemigos se aliaran a los invasores, o aprovecharan la ocasión para “confederarse contra los españoles”. La idea tenía un antecedente de tiempos de Góngora en que el mismo afirmaba que "según el estado presente la defensa que tiene es levantar la gente y ganado y retirarlo” preparar luego la recuperación del puerto desde la 
campaña $\underline{29}$.

Como otros gobernadores habían observado, para Salazar, la mejor defensa del puerto era su río, sembrado de bancos de arena que imposibilitaban un repentino y desapercibido desembarco.

Completando su informe con apreciaciones más políticas, Salazar se mostraba preocupado luego por la situación de pobreza y postergación en que se hallaba el vecindario, haciéndose eco de un reclamo que se repetía desde el siglo anterior: “pudiera ser que la conmiseración de Su Majestad mitigara en parte la prohibición, y se les concediera algo que fuera lícito, fijo y permanente (...) con esto crecería esta ciudad en lustre y número”.

El escrito finalizaba con una evaluación de la experiencia de la fallida primera Audiencia de Buenos Aires. Para su primer y único presidente, fue acertado cerrarla. Porque uno de sus objetivos fue el de "aumentar la vecindad por la ocurrencia de las demás provincias de su distrito", pero ni siquiera ofreciendo los oficios “de balde”, fue posible cubrir los cargos necesarios para su funcionamiento. Las penas de cámara eran tan mínimas que no alcanzaban siquiera para cubrir los salarios. Además, el objetivo de frenar las arribadas forzosas había fracasado de plano: "aunque estuviera aquí el Consejo de las Indias no las pudiera evitar, pues consisten en los accidentes del mar, o en la malicia de quien las hace”. Para Salazar, el mejor lugar hubiera sido Córdoba, por su ubicación geográfica “intermedia”, y por ser una ciudad abastecida, poblada e ilustrada.

El texto no fue desechado por el Consejo. Luego de ser analizado se dispuso que fuera remitido a su sucesor, Andrés de Robles.

Robles coincidía en los fundamentos del proyecto de Salazar,

...que el puerto de Buenos Aires es la llave y puerta principal de este reino, provincias del Tucumán, Paraguay, reino de Chile y provincia de Cuyo de aquella jurisdicción que está al pie de la cordillera (...) y si le ocupasen los enemigos (lo que Dios no permita) se apoderarían de ellas, es tan cierto como manifiesto a su majestad por tan diversos y repetidos informes...

Subrayaba, además, lo que más preocupaba a los estrategas militares de Madrid:

...como todos los enemigos y naciones del norte que tanto le desean, y no habiendo más entrada de estos reinos que este puerto y el de Cartagena, se debe tener con el cuidado y resguardo que conviene y pide materia de tanta gravedad y consecuencia para esta monarquía $\underline{30}$.

Para el nuevo gobernador, era correcta la estrategia de retirar caballada, tropa y armamento hacia el interior, pero Salazar no había tenido tiempo de recorrer mejor la campaña para notar que había otros posibles emplazamientos para fortificar. Antes de responder, Robles realizó un reconocimiento del territorio desde el río Saladillo, en Samborombón, hasta el Arrecifes. Después de eso, descartó la posibilidad de continuar la construcción del fuerte sobre el río Luján: "no se puede aplicar más formal ni propiamente el proverbio de poner puertas al campo como en este caso", pues el sitio previsto no era paso preciso del río, además de ser inundable y haber sido atacado por los indios. 
Según su parecer, el mejor lugar se encontraba en Arrecifes en un

...paso común, que hoy tiene, que llaman de la estancia de Doña Isabel Martel, o hacia su nacimiento donde llaman El salto y cabezadas de los Arrecifes, todo en derechura y más breve a las dichas provincias de adentro de suerte que el fuerte en la parte referida ni sirve para cubrir y ocupar el paso.

Allí también había más ganado para sostener a la población refugiada, y mejor ubicación para despachar pedidos de socorro a las provincias del interior.

Por otro lado, desestimaba la idea de Salazar de disponer de un número elevado de tropas fuera de Buenos Aires desarmando la ciudad. Su consejo fue "defender y mantener este puerto con todas las fuerzas posibles, hasta verter la última gota de sangre, porque los que mantienen los reinos y provincias son las fortalezas de los puertos y costas de mar y río”, pues si Buenos Aires cayese, “¿de que serviría tener el fuerte en el Río Luján las diez o doce leguas de esta ciudad?”.

Previendo que un ataque se hiciera efectivo, coincidía con su antecesor en disponer de reservas de pólvora en lugares alternativos, en Arrecifes o en Baradero, pueblo al que la zumaca del fuerte podía arribar sin dificultad,

...es navegable para lanchas y balsas de buen porte y es el paso de todas las embarcaciones que vienen del Paraguay, Corrientes y Santa Fe, de suerte que puesta en este paraje del Baradero, o estancia, las armas, municiones, artillería y algunos instrumentos de gastadores, están parados fines muy principales.

En alguno de esos lugares había que construir una torre de buena calidad donde almacenar no sólo pólvora, sino también tabaco y yerba "que es un mantenimiento en estos habitadores tan natural como pan y carne”.

Después de descalificar las obras realizadas por Salazar en el fuerte -“cierto que estas obras suenan más de lo que cuestan y demuestran las tasaciones”-, descartaba también la posibilidad de una apertura comercial. En principio porque en los últimos años habían arribado al puerto numerosos registros. Si a eso se sumaba la periódica llegada del situado, no había más necesidad que la de proveerse de un número de esclavos mínimo, porque en exceso,

...servirían sólo para hacer mercancía (...) se llenaría este puerto de mercaderías de Francia, Inglaterra y Holanda y por consiguiente todas estas provincias hasta Potosí y Chile, sin que pudiera haber remedio en lo contrario y cuando viniera algún navío de registro no hallara salida de su hacienda y se perdieran totalmente, porque los géneros que entraran del Río de Janeiro, como a menor gasto y costas los habían de dar a la mitad de precio que los de registro.

Muchos años después, cuando Buenos Aires viera ondear el pabellón británico en su fortaleza, fue desde la campaña que se organizó la reconquista de la plaza. 


\section{Hombres en armas}

Varios temas se reiteraban en la correspondencia de los gobernadores de Buenos Aires: si los pedidos de permisiones de comerciar recorrieron el siglo desde antes mismo de la división de la provincia, y más allá del siglo XVIII, la otra demanda fue la de la dotación de hombres para hacer efectiva la capacidad defensiva de la ciudad. Todos los gobernadores coincidieron no sólo en la insuficiente $-\mathrm{y}$ a veces hasta ineficiente- capacidad de respuesta de la propia vecindad en armas, sino también en la necesidad de disponer de tropa pagada. Una pretensión que debió esperar a 1631 para hacerse realidad.

En 1619, Góngora había advertido la escasa cantidad de hombres disponibles: unos 120 hombres distribuidos en cuatro tropas de caballos y una compañía de infantería. Al máximo que podía aspirar era a movilizar unos 200 hombres en armas. En poco tiempo, Góngora se jactaba de haber logrado reparar los 48 mosquetes y arcabuces que había encontrado en mal estado, así como las 9 piezas de artillería que halló sin municiones ni pólvora. Con la poca gente disponible, logró organizar dos compañías de caballos ligeros y lanzas y otra de infantería $\frac{31}{\text {. }}$

En tiempo del gobernador Céspedes se mantuvo la misma estructura defensiva: "de criollos de la tierra hay dos compañías y de la misma, una de infantería”, a lo que se logra sumar "otras dos de indios forasteros de a caballo que están sirviendo en esta tierra” 32 .

Aunque el tema excede los límites de este trabajo, es necesario mencionar que un factor siempre gravitante en el equilibrio bélico de la frontera hispano portuguesa fue la disponibilidad de mano armada indígena, cuya mayor concentración física se vivió en las reducciones jesuíticas, capaces no sólo de disponer de miles de hombres, sino también de armarlos y entrenarlos en el uso efectivo de armas europeas. En 1635, la compañía había pedido autorización para armar a los indios ante las recurrentes bandeiras que desde tierras lusitanas diezmaban las reducciones $\underline{33}$.

Combinadas con tácticas y armamento nativo, esas milicias guaraníes fueron capaces de lograr su primer triunfo bélico en 1641, en la batalla de Mbororé, donde guaraníes conducidos por sacerdotes que habían pasado por las guerras de Flandes fueron capaces de derrotar a un ejército paulista de más de 3500 hombres (Avellaneda y Quarleri, 2007). Del mismo modo, la presencia de más de 3.000 indios fue, en 1680, un factor decisivo en la victoria del Gobernador Garro en la toma de Colonia do Sacramento (Takeda, 2016).

La composición multiétnica de las fuerzas armadas se completaba, además, con integrantes afroamericanos. Para 1664, la guarnición disponía de una compañía de mulatos de caballería con 30 hombres y otra de infantería con 47 (Goldberg, 2003).

La necesidad -y la decisión concreta- de recurrir a tropas y recursos locales demuestra que si bien las preocupaciones de los máximos representantes del gobierno de la monarquía y sus agentes en el territorio enfocaban la cuestión militar como central, su concreción efectiva no podía esperar que se llevara a cabo desde Madrid.

La primera dotación fija de tropa con destino al Río de la Plata recién llegó a fines de 1631. Antes de embarcar para el Río de la Plata, el gobernador Dávila había detallado una serie de pedidos, en la misma solicitud de licencia para embarcar: un año de sueldo adelantado, permiso para embarcar en 
Porto y poder llevar ocho criados, un barbero, un cirujano y sus mujeres. Además, lo necesario para la defensa del puerto: 200 hombres, 200 mosquetes, otros tantos arcabuces, velas, cuerda, pólvora, así como poder llevar al soldado don Pedro Espinoza Maldonado “para que le ayude a poner en buena disciplina a los moradores” $\underline{34}$.

De los 200 hombres que había solicitado, apenas logró reclutar unos 45, luego sumó otros 32 en Río de Janeiro, a quienes debía sostener personalmente (Marchena Fernández, 1985). Al llegar a Buenos Aires, la paga del salario de esos soldados ocasionó no sólo la resistencia de los oficiales de la Real Hacienda, sino también la reprobación del visitador Garabito, quien denunció lo improcedente del cargo de esos costos a las Reales Cajas. Dávila se defendió diciendo que "ni su Majestad quiere la plata para hacer tesoro, ni el Gobernador debía ser acusado porque el pobre soldado viva...”. La defensa de Dávila demostró que la falta de una paga regular - un problema que sería crónico durante todo el período colonial- era la causa de las numerosas deserciones que ni siquiera las condenas a muerte lograban evitar. La disputa siguió al punto de ser derivada al Consejo de Indias, y de que fuera embargado el sueldo del propio gobernador y los retiros de plata que hacían posible el mantenimiento de aquella tropa, así como el de las obras de refacción $\underline{35}$.

La dotación de hombres para el fuerte, así como el envío de pertrechos que se concretó en tiempos del gobernador Dávila, tenía como telón de fondo contextos sumamente críticos para la geopolítica regional: la caída de Pernambuco en poder de los holandeses (Valladares, 2006) y el recalentamiento de las relaciones interétnicas en el interior de la gobernación, que desembocaron en el despoblamiento de Concepción del Bermejo (Faberman, 2016).

Dos levas, una en 1660 y otra en 1669 aportaron casi 200 hombres más de tropa regular, hasta llegar en tiempos del gobernador Salazar a unos 300 hombres. La leva de 1674, con más de 300 soldados arribados, eleva el plantel a un número ideal.

La dificultad para el reclutamiento se puede explicar por la crisis demográfica que en las principales regiones proveedoras de tropas se estaba viviendo, además de la intensificación de los conflictos en el propio continente europeo (Ribot, 2006).

Para 1676, el gobernador Andrés de Robles hablaba de 600 infantes “a orden y voluntad expresa de su Gobernador y Capitán General que rondan playas y caminos de mar y tierra” $\underline{36}$. Para entonces, la situación pareció estabilizarse, al menos momentáneamente, en palabras del propio gobernador en cuanto a la regularidad de los pagos del situado, que el Virrey había cumplido puntualmente. Por ello, no resulta raro que la misma comunicación observe que "la gente de la guarnición se conserva en muy buena forma y no se me ha huido hasta hoy ningún soldado” $\underline{37}$. Una estabilidad que no se sostendría en el tiempo, pues al final del período se viviría otra sucesión de notables atrasos en los pagos.

Ante el peligro omnipresente de una invasión enemiga, el propio Robles insistió en reiteradas ocasiones por el envío de otros 200 hombres, sumados a un refuerzo de unas seiscientas familias guaraníes provenientes de las misiones jesuíticas (Torre Revello, 1939).

Ya para entonces, la guarnición se había constituido en un factor gravitante en la vida de la ciudad. 
Visto en perspectiva, el proceso de dotación de tropa efectiva y regular no fue significativo ni constante en el tiempo. El peso de la defensa del territorio siguió recayendo sobre tropas milicianas, reforzadas en eventuales arribos de tropas y armas en coyunturas particulares, como las que se reseñan.

Desde el punto de vista demográfico, la presencia del presidio fue importante por el aporte de nuevos inmigrantes de origen peninsular $\underline{38}$, además de la posibilidad de ascenso para los jóvenes militares criollos. $\frac{39}{}$ De su importancia nos habla, por ejemplo, el conflicto desatado entre el gobernador Andrés de Robles y el obispo, por la pretensión del primero de que los entierros de los soldados fueran hechos de forma gratuita $\underline{40}$. Fue también un elemento nada despreciable en la economía del puerto, pues la oficialidad, con la complicidad de funcionarios de las más altas esferas, recibía la paga en metálico después de haber adelantado en vales o en mercaderías los salarios de la tropa (Birocco, 2015). Además, el fuerte aparecía mencionado en múltiples ocasiones como almacén de reservas de herramientas de todo tipo: desde acero, palas, hachas, hasta desjarretadoras. Estas últimas eran una especie de cuchilla que, atada al extremo de una lanza, se utilizaba para inmovilizar al ganado cimarrón en las vaquerías $\underline{41}$.

La remisión de los situados tuvo períodos de mucha irregularidad, lo que, aun cuando representaba un grado de incertidumbre e inestabilidad para la economía local, fue aprovechado por mercaderes, gobernadores y oficiales como terreno fértil para la especulación. Desde el mismo transporte de esos caudales desde el Alto Perú hasta su adelanto en fiado a la tropa fue un provechoso mecanismo de interés y ganancia (Saguier, 1989). La cifra osciló de unos $\$ 67.000$ en 1645, a más de \$200.000 en 1684. En 1677, el Gobernador Andrés de Robles hablaba de un monto anual regular de más de $\$ 120.000 \underline{42}$. Zacarías Moutoukias resalta la importancia de los situados:

...las Reales cajas de Potosí contribuían con el llamado situado, una remesa de metales preciosos que comenzó hacia 1650 y aumentó progresivamente en valor y regularidad, hasta alcanzar desde 1670 un ritmo teóricamente anual. Las sumas eran muy importantes. El promedio anual de lo que se enviaba a finales del siglo permitía comprar unos 500/600 esclavos. El monto total de las remesas hechas entre 1693 y 1697 equivalía a dos veces el valor total de las exportaciones de ganado en pie hacia el interior durante esos mismos años (Moutoukias, 2000).

En múltiples ocasiones vemos a Capitanes dueños de tiendas y pulperías, y aunque la Real Audiencia les prohibió negociar en 1686, los seguimos encontrando al frente de sus negocios por mucho tiempo más (Goyret, 1999). Esta situación motivó las más airadas protestas, que llegaron a vista misma del monarca, como la petición del procurador general de la ciudad, Don Gabriel de Aldunate, que en 1695 se quejaba de que "muchos soldados y oficiales del Presidio se ejercitan en comerciar, y atienden más a sus conveniencias que al real servicio" 43 . Ciertamente, su presencia en Buenos Aires significaba no sólo un poder de defensa instalado, sino también un importante factor de apoyo para el gobernador, a cuyo mando directo se encontraban ${ }^{44}$. 
Tabla 2. Levas de tropas a Buenos Aires $\underline{45}$

\begin{tabular}{|c|c|c|c|}
\hline Año & Navíos & Tropa & Provisiones \\
\hline 1631 & & 75 & $\begin{array}{l}\text { Armas, municiones, pólwora } \\
\text { y otros pertrechos }\end{array}$ \\
\hline 1645 & & 100 & No consta \\
\hline 1660 & \begin{tabular}{|lll} 
Nuestra Señora & de \\
Aranzazu & & \\
\end{tabular} & 69 soldados & $\begin{array}{l}\text { Armas, municiones y otros } \\
\text { pertrechos }\end{array}$ \\
\hline 1669 & $\begin{array}{l}\text { San Hermenegildo, San } \\
\text { Miguel }\end{array}$ & 125 soldados & $\begin{array}{l}\text { Vestimentas, armas, } \\
\text { municiones, pólwora y otros } \\
\text { pertrechos }\end{array}$ \\
\hline 1674 & $\begin{array}{l}\text { Nuestra Señora del } \\
\text { Rosario; Nuestra Señora de } \\
\text { la Soledad y Santa María } \\
\text { de Lubeque }\end{array}$ & 338 & No consta \\
\hline 1681 & $\begin{array}{l}\text { Nuestra } \quad \text { Señora } \\
\text { Rosario; San Miguel y las } \\
\text { ánimas y } \\
\text { del Pópulo }\end{array}$ & 302 & $\begin{array}{l}\text { "Otros tantos vestidos de } \\
\text { munición para ellos" }\end{array}$ \\
\hline
\end{tabular}

\section{Portugueses frente a Buenos Aires: Colonia del Sacramento}

Depuesto el gobernador Andrés de Robles de su cargo, acusado de diversas irregularidades, el virrey designó como Interino a José de Garro, maestre de campo e, igual que sus antecesores, caballero de la Orden de Santiago. Es interesante que, aun tratándose de un Gobernador interino designado con objeto de investigar las irregularidades de la gestión del depuesto Andrés de Robles, también se tratase de un perfil similar al de los hombres designados por la Corona. En efecto, el virrey del Perú, enfatizaba que su elección se fundaba en "ser soldado tan graduado y conocido (...) que no debe quedar sin persona del valor y experiencia militar” que la situación de Buenos Aires ameritaba $\underline{46}$.

El hecho más significativo de su gobierno fue el desalojo de los portugueses de Colonia del Sacramento en 1680. La expedición organizada por Garro y liderada por el maestre de campo Antonio de Vera Mujica lograba recuperar el enclave, pero el tratado provisional firmado en Lisboa entre ambas potencias, dispuso su devolución a la corona lusitana, aunque a Garro se lo premió con la designación de gobernador y presidente del Reino de Chile. Antes de emprender la toma de Colonia, el gobernador solicitaba una extensa lista de armamentos, entre los que incluía 200 carabinas vizcaínas, 200 mosquetes, 200 arcabuces, 100 astas de picas, 200 quintales de pólvora, espadas, pistolas, bandoleras, acero, clavos, brea y otros elementos. Las anotaciones al margen dan cuenta de la urgencia de la respuesta y la celeridad en que se dispusieron los embarques de lo solicitado $\frac{47}{}$. El éxito de la campaña descansó, sin embargo, en la disponibilidad y movilización de tropas milicianas, especialmente de indios guaraníes (Avellaneda y Quarleri, 2007).

En pleno conflicto con Portugal, la dotación de hombres del presidio alcanzaba ya los 593 hombres $\underline{48}$. 
Tabla 3. Dotación de hombres del Presidio de Buenos Aires en 1681

\begin{tabular}{|c|c|c|}
\hline Formación & Descripción & $\mathbf{N}$ \\
\hline Plana Mayor & $\begin{array}{l}1 \text { Sargento Mayor, } 2 \text { ayudantes, } 1 \text { capellán, } 1 \\
\text { mayordomo de artillería, } 1 \text { condestable, } 7 \\
\text { artilleros y } 1 \text { armero }\end{array}$ & 14 \\
\hline $\begin{array}{l}1^{\circ} \text { Compañía de caballos, } \\
\text { corazas y carabinas }\end{array}$ & $\begin{array}{l}1 \text { capitán, } 1 \text { teniente, } 1 \text { alferez, } 1 \text { trompa, } 3 \\
\text { cabos de escuadray } 55 \text { plazas sencillas }\end{array}$ & 62 \\
\hline $\begin{array}{l}2^{\circ} \text { Compañía de caballos, } \\
\text { corazas y lanzas }\end{array}$ & $\begin{array}{l}1 \text { capitán, } 1 \text { teniente, } 1 \text { alférez, } 1 \text { trompa, } 3 \\
\text { cabos de escuadray } 47 \text { plazas sencillas }\end{array}$ & 54 \\
\hline $1^{\circ}$ Compañía de infantería & $\begin{array}{l}1 \text { capitán, } 1 \text { paje de jineta, } 1 \text { alférez con su } \\
\text { abanderado, } 1 \text { sargento, } 2 \text { tambores, } 4 \text { cabos } \\
\text { de escuadra y } 106 \text { plazas sencillas }\end{array}$ & 117 \\
\hline $2^{\circ}$ Compañía de infantería & $\begin{array}{l}1 \text { capitán, } 1 \text { paje de jineta, } 1 \text { alférez con su } \\
\text { abanderado, } 1 \text { sargento, } 4 \text { cabos de es cuadra } \\
\text { y } 109 \text { plazas sencillas }\end{array}$ & 120 \\
\hline $3^{\circ}$ Compañía de infantería & $\begin{array}{l}1 \text { capitán, } 1 \text { paje de jineta, } 1 \text { alférez con su } \\
\text { abanderado, } 1 \text { sargento, } 2 \text { tambores, } 4 \text { cabos } \\
\text { de escuadra y } 98 \text { plazas sencillas }\end{array}$ & 109 \\
\hline $4^{\circ}$ Compañía de infantería & $\begin{array}{l}1 \text { capitán, } 1 \text { paje de jineta, } 1 \text { alférez con su } \\
\text { abanderado, } 1 \text { sargento, } 2 \text { tambores, } 4 \text { cabos } \\
\text { de escuadra y } 106 \text { plazas sencillas }\end{array}$ & 117 \\
\hline
\end{tabular}

Asimismo, una Real Cédula daba cuenta de la decisión del Consejo de que se compusiera el presidio de 850 hombres sin contar oficiales ni cabos $\underline{49}$, lo que coincide con el arribo, pocos meses después, de 302 nuevos soldados.

La operación militar, aunque contradicha por las gestiones diplomáticas metropolitanas, había demostrado la utilidad práctica de contar con presencia militar efectiva en Buenos Aires. Como en otras oportunidades, la coyuntura fue aprovechada por los indios, en este caso, pampas y serranos, “gentío muy bárbaro e irreductible que habita en los desiertos y campaña”, quienes “empezaban a mostrar su osadía más que otras veces, haciendo muertes, robos, causando terror y otras vejaciones”, situación que obligó al gobernador a organizar una maloca que concluyó con la muerte de unos 40 "indios gandules, los principales robadores y matadores”, y el reparto de otros 60 entre los vecinos que participaron $\underline{50}$.

Antes de partir a su nuevo destino, Garro designó como sucesor interino al cabo y gobernador de la caballería del fuerte, José de Herrera y Sotomayor (Torre Revello, 1939). Se trataba de otro militar de carrera, que contaba entre sus méritos haber participado de campañas militares en Flandes, Extremadura y Cataluña. Y es justamente por eso que fue seleccionado para ser cabo y gobernador de la caballería del Presidio (Birocco, 2015). Y en ese cargo lo encontró la novedad de la partida de Garro a Chile. Fue el encargado de cumplir la orden de devolución de Colonia do Sacramento a los portugueses en cumplimiento del Tratado Provisional en 1682. Ese mismo año, dispuso la edificación del fuerte de San Sebastián (Molina, 2000).

Agustín de Robles, el último gobernador del siglo XVII, debió enfrentar una de las coyunturas más críticas de la historia militar del período: luego de crónicas demoras en la llegada del situado, la soldadesca llegó a saquear casas del vecindario. Y aun cuando el gobernador logró contener la situación, la acusación de desprotección de la tropa llegó a su juicio de residencia (Birocco, 2015). Estos crónicos atrasos en los pagos a la tropa, sumados a la lentitud, intermitencia y fragmentación 
de la provisión de recursos, parecen vivir un verdadero punto de inflexión hacia 1680, cuando la presencia portuguesa en Colonia del Sacramento habría de transformar los malos pronósticos en una candente realidad.

\section{A modo de conclusión}

"La guerra es mi elemento. En la guerra me he criado, como Su Majestad tiene muy larga noticia” Diego Marín Negrón, 1610

Las palabras del gobernador Negrón, nos permiten dar una pincelada final a la estampa de la personalidad de estos gobernadores. Pero más aún, nos ayuda a percibir la importancia que la cuestión militar tuvo en la historia del Buenos Aires colonial más temprano.

Desde el mismo momento de la designación de los candidatos a ocupar la gobernación del puerto bonaerense, vemos esa preocupación por la protección del territorio: la alta estima que los consejeros del rey tenían por personas que tuvieran inteligencia en asuntos de guerra. Aun cuando el gobierno suponía otras atribuciones centrales para la subsistencia de la monarquía -tales como la administración de justicia-, el siglo estuvo signado por un recurrente y casi obsesivo cuidado de los asuntos defensivos y ofensivos.

La correspondencia de estos funcionarios siempre puso en primer término estas cuestiones: reclamaban tropas, solicitaban pertrechos o informaban de cuestiones directamente vinculadas a la materia, tales como obras de defensa, recogidas de caballadas, persecuciones de indios enemigos y alardes con milicias y tropas regulares.

La preocupación por la cuestión militar también incluía a la élite local. En numerosas ocasiones el Cabildo local presentaba peticiones al gobernador, o incluso a la propia Corte de Madrid, a través de procuradores, para sustentar en el riesgo militar la necesidad de fomentar el crecimiento de la ciudad como forma de hacer posible la subsistencia de Buenos Aires $\underline{51}$.

A esa preocupación hay que agregar el interés concreto por aprovechar el impacto económico que la presencia de un presidio y de sus hombres significaba para un enclave que supo eludir las restricciones que pretendían cerrarlo al tráfico atlántico. Comercio local y presidio fueron un dinámico binomio llamado a sobrevivir largamente al cambio de siglo. Durante la gestión de estos gobernadores, las órdenes, pragmáticas y reales cédulas que llegaban desde Madrid, insistían con la importancia neurálgica de cuidar hasta los detalles más particulares de la defensa de Buenos Aires. Finalmente, fuera como argumento de las denuncias o de los descargos de los gobernadores, "lo militar” recorría sus juicios de residencia en forma reiterada $\underline{52}$.

La coyuntura geopolítica europea del siglo XVII estuvo atravesada por conflictos que, a la vez que aumentaban la alarma de las autoridades metropolitanas, condicionaba la capacidad de dar respuesta a las urgencias defensivas y ofensivas de ultramar. Y desde la otra orilla, además de las consecuencias locales de las decisiones diplomáticas europeas, había que dar respuesta cotidiana al peligro indígena que en distintos frentes acechaba y ponía en riesgo la supervivencia de los poblados castellanos. 
La cuestión militar se nos presenta entonces como un elemento central en la configuración de esta sociedad periférica y fronteriza. Aun así, paralelamente al sostenido proceso de militarización del estilo de gobierno que se verificó en relación a Buenos Aires, su correlato concreto, como hemos señalado, reconoció un recorrido mucho más vacilante. Limitaciones de todo tipo hicieron que esa preocupación por la defensa y posesión efectiva del territorio no se tradujera en acciones concretas con la misma intensidad, por lo menos hasta la crítica coyuntura de 1680, cuando los temores de la presencia efectiva de potencias enemigas se hicieron realidad. Incluso entonces, la clave decisiva del triunfo castellano estuvo en la disponibilidad de recursos propios -las milicias guaraníes, de Santa Fe, Córdoba y Corrientes (Birolo, 2014)- más que en los recursos suministrados por la metrópoli. Una demostración de la eficacia del criterio básico de movilización militar general (Pérez Prendes, 1989).

En este sentido, aun cuando sea innegable que en términos generales la monarquía hispánica viera aumentar el protagonismo político y administrativo de los profesionales de las armas en el período borbónico, el caso del Río de la Plata demuestra cóomo los rasgos iniciales de ese proceso pueden verse mucho antes, y que la concepción burocrática inspirada en criterios disciplinarios de raigambre castrense, también formó parte de las intenciones -al menos- de los Austrias. (Abásolo, 2005; Eisa-Barroso, 2016)

Si bien hemos enfocado los primeros pasos de ese proceso, resulta sustancial avanzar en el estudio de un proceso que explique la configuración de las relaciones sociales, políticas y económicas de una región fronteriza en perspectiva de larga duración.

\section{Notas}

1 La propia división del territorio reconoce causas de geopolítica militar. En uno de los tantos pedidos de consideración acerca de la conveniencia de dividir la jurisdicción de la enorme provincia del Río de la Plata, el gobernador Hernando Arias de Saavedra argumentaba que un reciente ataque de los portugueses contra los indios del Guayrá, así como el riesgo de los ataques de indios enemigos sobre las ciudades españolas, hacían necesaria la medida. (Torre Revello: 1939)

$\underline{2}$ Archivo General de Indias (En adelante AGI) Charcas, 27 R.10; N 99. Carta del Gobernador Hernando Arias de Saavedra, 6/07/1616. Subrayado en el original.

3 AGI. Charcas. 27 R 11. º 140. Carta del gobernador Diego de Góngora. 10/05/1621

4 AGI. Chile. 41. N¹5. Informaciones, Diego Páez de Clavijo. 1616

5 AGI. Indiferente 161 N.184. Méritos de Mendo de la Cueva y Benavídez, Capitán de Infantería, Consejero de Guerra. 21/08/1635

6 AGI. Charcas. 91. ํ⒌ Informaciones, Andrés de Sandoval. 1637

Z AGI. Indiferente. 121 № 148. Méritos de Alonso Mercado y Villacorta. 1670

$\underline{8}$ AGI. Indiferente. 122 N 63. Servicios de Andrés de Robles. 1672 
9 AGI. Escribanía 903 A. Visita a las Cajas Reales de Buenos Aires. 1632

10 AGI. Charcas 28. R9 N 73. Carta del Gobernador Andrés de Robles. 10/07/1676

11 De la misma Real Cédula de su erección de 1661 se desprende esa intención: “Teniendo consideración a lo que conviene que las provincias del Río de la Plata, Tucumán y Paraguay sean bien gobernadas, así en lo militar como en lo político (...) que ésta resida en la de la Trinidad del puerto de Buenos Aires y que se componga de un Presidente, tres Oidores y un Fiscal, y de los demás ministros que conforme a sus ordenanzas debiere haber, y que el dicho mi Presidente sea de capa y espada, y en quien concurran inteligencia en lo militar, para que juntamente sea Gobernador y Capitán General de las Provincias del Río de la Plata” AGI. Escribanía 894 A.

12 AGI. Charcas.1, N 95 Consulta del Consejo de Indias 19/04/1596; AGI Charcas 1, N 99 Consulta del Consejo de Indias 20/06/1596; AGI Charcas 1, $N^{\circ} 104$ Consulta del Consejo de Indias 23/12/1596

13 AGI. Charcas. 27, R 8, n² 22. Carta del gobernador Hernando Arias de Saavedra. 05/04/1604

14 En numerosas oportunidades se denunciaron excesos en la justificación de esos gastos, como en 1677, cuando el gobernador Agustín de Robles criticaba las obras realizadas por su antecesor: “cierto que estas obras suenan más de los que cuestan y demuestran las tasaciones” AGI. Charcas 278. “1667-1716. Expediente sobre la fortificación de Buenos Aires”

15 AGI. Charcas. 27, R 9, N 74. Carta del gobernador Diego Marín Negrón. 30/04/1610

16 AGI. Charcas. 27, R 9, N 120. Carta del gobernador Diego de Góngora. 20/07/1619. En otra carta fue más elocuente: "lo que llaman fuerte, unas tapias de tierra muerta, la mitad caídas y con el primer aguacero se terminaron de caer...” AGI. Charcas. $27 \mathrm{R} 9, \mathrm{~N}^{\circ} 126$. Carta del gobernador Diego de Góngora. 30/07/1619.

17 AGI. Charcas. 27, R 11, N 129. Carta del gobernador Diego de Góngora. 02/03/1620

18 AGI. Charcas. 27, R 11. N 132. Carta del gobernador Diego de Góngora. 03/02/1620. Allí constan las copias de ambas Reales Cédulas (16/04/1618 y 18/03/1619). Ambas fueron respondidas por el gobernador, desestimando su urgencia, por la relativa paz con los indios, así como la imposibilidad material de disponer de tropas, municiones y materiales.

19 AGI. Charcas. 28 R 3. № 9. Carta del gobernador Francisco de Céspedes. 25/09/1625

$\underline{20}$ AGI. Charcas. 28 R 3. N 10. Carta del gobernador Francisco de Céspedes. 10/05/1626

$\underline{21}$ AGI. Charcas. 28 R 3. N 11. Carta del Gobernador Francisco de Céspedes. 10/05/1626

$\underline{22}$ AGI. Charcas. 28 R 3. N 19. Carta del Gobernador Francisco de Céspedes. 20/09/1628

$2 \underline{3}$ AGI. Charcas. 28 R 4, N 50. Carta del Gobernador Pedro Esteban Dávila. 1638.

$\underline{24}$ AGI. Charcas. 28 R 5. N 51. Carta del gobernador Mendo de la Cueva y Benavídez. 9/11/1638

$\underline{25}$ AGI. Charcas. 28 R 7. № 62. Carta del gobernador Pedro Baigorri. 06/12/1653

26 AGI. Charcas 278. “1667-1716. Expediente sobre la fortificación de Buenos Aires”. 
27 La designación original preveía el nombramiento del antecesor de Salazar, el gobernador Mercado y Villacorta. Para cuando debió hacerse efectiva, el mando recayó en su sucesor. Torre Revello afirma que aquella primera designación fue revocada por la Corona luego de comprobarse la autorización hecha por Mercado para comerciar con navíos holandeses. (Torre Revello, 1939). Para el caso, el perfil de Mercado y Salazar era similar: ambos militares de carrera y prestigio.

$\underline{28}$ Archivo Histórico Nacional. Diversos. Colecciones 43. Nº 13

$\underline{29}$ AGI. Charcas. 27 R 11, N 148. Carta del gobernador Diego de Góngora. 15/07/1621

30 AGI. Charcas, 278. “1663-1716 Expediente sobre la fortificación de Buenos Aires”.

31 AGI. Charcas. 27 R 11 №120. Carta del gobernador Diego de Góngora. 20/07/1619. Más adelante observaba que con la poca gente que había logrado reclutar en esas tres compañías organizaba alardes y patrullas, siempre vigilante, y habiendo "señalado puestos y dado orden para cualquier invasión que suceda”. Pero la solución era "el envío de 300 soldados para su buena custodia y defensa con armas y municiones, porque aquí no hay oficiales ni aderezo para hacerlas” AGI. Charcas. 27 R 1. N 133. Carta del gobernador Diego de Góngora. 03/02/1620.

$\underline{32}$ AGI. Charcas 28 R 3. Nº41. Carta del gobernador Francisco de Céspedes. 30/08/1631

33 AGI. Charcas 28 R 4 N49 Carta del gobernador Pedro Esteban Dávila 16/09/1632

34 AGI. Indiferente 2107 N.83. Licencia a Pedro Esteban Dávila para pasar al Río de la Plata, 1629

35 AGI. Charcas. 28 R 4, N 50. Carta del gobernador Pedro Esteban Dávila. 1638.

$\underline{36}$ AGI Charcas 28, R9, № 73. Carta del gobernador Andrés de Robles. 10 de Junio de 1676.

37 AGI. Charcas 28 R 9, № 70. Carta del gobernador Andrés de Robles.01/06/1676.

38 Una Real Cédula fechada en 2 de agosto de 1679, disponía que no se castigara a los soldados que contrajesen matrimonio, "sino que se les deje toda la libertad que por derecho les compete". AGI. Charcas. 28 R 10. N 108. Carta del gobernador José de Garro. 01/03/1681.

39 En 1680 el gobernador presentaba un informe de "los sujetos beneméritos y dignos de mercedes”, destacando a vecinos de Buenos Aires y Santa Fe por sus méritos militares. AGI Charcas. 28 R10. N¹02. Carta del gobernador José de Garro. 12/04/1680.

40 AGI. Charcas. 28 R 9. N81. Carta del gobernador Andrés de Robles. 14/02/1678

$\underline{41}$ Archivo General de la Nación. IX 23.3.9. Almacenes reales. Guerra. Pertrechos.

42 AGI. Escribanía 892 B. Juicio de Residencia al gobernador Jerónimo Luis de Cabrera. 1647; AGI. Contaduría 1877. AGI Charcas, 278. “1663-1716. Expediente sobre la fortificación de Buenos Aires”.

$\underline{43}$ Se reiteraba así una petición que estaba incluida en un extenso memorial que el Cabildo presenta al rey con medidas de fomento para la ciudad, en la que uno de sus puntos solicitaba la prohibición para soldados y oficiales de habilitar tiendas y pulperías "pues en ellas estancan el comercio libre, y no pudiendo dar los vecinos los frutos al mismo precio (...) se ven obligados a vendérselos al por mayor a los dichos militares a menos precio”. (Levillier, 1918) 
44 Así lo señala Jorge Gelman: "Hasta la década del 30 del siglo XVII no existe un cuerpo armado profesional a las órdenes del Gobernador Capitán General, sino que su "ejército" son las milicias formadas por los vecinos que en época de guerra o amenaza debían dejar sus negocios para ponerse a las órdenes del Gobernador; y es obvio que estos vecinos se veían más identificados con su Cabildo que con un Gobernador venido de otros lados” (Gelman, 1985)

45 Fuentes: (Molina, 2000), (Pico, 1992) y (Marchena Fernández, 1985).

46 AGI. Charcas. 28 R 10. N 102. Carta del gobernador José de Garro. 12/04/1680

47 AGI. Charcas. 28 R 10. № 106. Carta del gobernador José de Garro. 12/04/1680

48 AGI. Charcas. 28 R 10 N 109. Carta del gobernador José de Garro. 02/03/1681

49 La Real Cédula estaba fechada en 26 de febrero de 1680, y llegó junto con advertencias de una inminente fundación portuguesa en el Río de la Plata. AGI. Charcas. 28 R 10. N 108. Carta del gobernador José de Garro. 03/01/1681.

$\underline{50}$ AGI. Charcas. 28. R 10 N¹10. Carta del gobernador José de Garro. 04/03/1681

$\underline{51}$ En 1632 el Cabildo enviaba a Madrid a sus procuradores con instrucciones de pedir la creación de una Audiencia, de rogar la autorización de permisiones comerciales y de aumentar la presencia de soldados en el Presidio. Archivo General de la Nación. Acuerdos del Extinguido Cabildo de Buenos Aires. Tomo VII Libros IV y V. Años 1629 a 1635. Buenos Aires, 1909. De la misma manera, en 1641, apenas llegada a Buenos Aires la nueva de la Rebelión de Portugal, se reseñaba en las actas el lamentable estado del fuerte, la poca defensa que la ciudad disponía por la falta de soldados y armas ante el inminente peligro de invasión lusitana. Archivo General de la Nación. Acuerdos del Extinguido Cabildo de Buenos Aires. Tomo IX Libros V y VI. Años 1640 a 1645. Buenos Aires, 1911.

$\underline{52}$ Los gobernadores muchas veces justificaban medidas que algunos vecinos consideraban “excesivas”, u otros funcionarios denunciaban como flagrantes violaciones a su jurisdicción (especialmente los jueces oficiales reales, cuando veían a los gobernadores retirar fondos de las Reales Cajas para gastos militares), por las necesidades del "Real Servicio", la urgencia de tomar medidas defensivas u ofensivas.

\section{Referencias bibliográficas}

Abásolo, E. (2005). Estilo militar de gobierno y disciplinamiento en la administración virreinal rioplatense bajo los borbones. Revista de Historia del Derecho, 33, 13-67.

Alvarez-Coca González, M. (1993). La concesión de hábitos de caballeros de las órdenes militares: procedimiento y reflejo documental (S. XVI-XIX). Cuadernos de historia moderna, 14, 277-297.

Avellaneda, M. y Quarleri, L. (2007). Las milicias guaraníes en el Paraguay y el Río de la Plata: alcances y limitaciones (1649-1756). Estudos Ibero-Americanos, 33(1), 109-132.

Batista González, J. (2007). España estratégica. Guerra y diplomacia en la historia de España. 
Madrid: Sílex.

Birocco, C. (2015). El Presidio de Buenos Aires entre los Habsburgo y los Borbones: el ejército regular en la frontera sur del imperio español (1690-1726). En E. Reitano, y P. Possamai (Coords.), Hombres, poder y conflicto. Estudios sobre la frontera colonial sudamericana y su crisis. (pp. 117150). La Plata: Universidad Nacional de La Plata.

Birolo, P. (2014). Militarización y política en el Río de la Plata colonial. Cevallos y las campañas militares contra los portugueses, 1756-1778. Buenos Aires: Prometeo Libros.

Boccara, G. (Editor) (2014). Colonización, resistencia y mestizaje en las Américas (Siglos XVI-XX). Quito: Ediciones Abya-Yala.

Chiri, O. (1973). Los Cerrillos del Pilar, Provincia de Buenos Aires. Síntesis de un interesante problema de arqueología histórica. Antiquitas, Vol. XVII, 16-18.

Dedieu, J. (1998). Los gobernadores de Lérida, Barcelona y Gerona en el siglo XVIII. Pedralbes, Revista de Historia Moderna, 18, 491-507.

Eissa-Barroso, F. (2016). De corregimiento a gobierno político-militar: el gobierno de Veracruz y la "militarización" de cargos de gobierno en España e Indias durante los reinados de Felipe V. Relaciones. Estudios de historia y sociedad, 37(147), 13-49.

Faberman, J. (2016). La construcción de un espacio de frontera. Santiago del Estero, el Tucumán y el Chaco desde el prehispánico tardío hasta mediados del siglo XVIII. Revista del Museo de Antropología, 9(2), 187-198.

Gandía, E. (1939). Historia de la Boca del Riachuelo. Buenos Aires: Talleres gráficos Virtus.

Gelman, J. (1985). Cabildo y élite local en Buenos Aires en el siglo XVII. HISLA Revista Latinoamericana de Historia económica y social, 6, 3-20.

Gelman, J. (2012). La economía de Buenos Aires. En R. Fradkin (Dir.), Historia de la Provincia de Buenos Aires, Tomo II: Buenos Aires de la Conquista hasta 1820. (pp. 85-121). Buenos Aires: EDHASA.

Goldberg, M. (2003). Milicias y tropas negras de Buenos Aires. Afroargentinos armados para defender a sus amos. Memoria y sociedad, 15, 37-51.

Goyret, T. (1999). Huestes, milicias y ejército regular. En Nueva Historia de la nación Argentina. Tomo II (pp. 351-382). Academia Nacional de la Historia. Buenos Aires: Planeta.

Guérin, M. (2000). La organización inicial del espacio rioplatense. En E. Tandeter (Dir.) Nueva Historia Argentina. Tomo II. La sociedad colonial (pp. 13-54). Buenos Aires: Editorial Sudamericana.

Lejonagoitia, G. (2014). Gobernar las Indias. Venalidad y méritos en la provisión de cargos americanos, 1701-1746. Almería: Editorial Universidad de Almería.

Levaggi, A. (1982). La primera Audiencia de Buenos Aires (1661-1672). Revista de Historia del derecho, 10, 9-120. 
Levillier, R. (1918). Correspondencia de la ciudad de Buenos Aires con los Reyes de España. Tomo III, 1660-1690. Buenos Aires: Municipalidad de la Ciudad de Buenos Aires.

Lewin, B. (Ed.) (1958). Descripción del Virreinato del Perú. Crónica inédita de comienzos del siglo XVII. Rosario: Universidad Nacional del Litoral.

Marchena Fernández, J. (1985). Las levas de soldados a Indias en la Baja Andalucía. Siglo XVII. En Andalucía y América en el siglo XVIII : actas de las IV Jornadas de Andalucía y América (pp. 93-117). Sevilla: Escuela de Estudios Hispanoamericanos.

Martínez Casado, G. (2002). La cofradía de los señores soldados del Presidio de Buenos Aires 1639-1762. En F. Barrios (Coord.). Derecho y administración pública en las Indias hispánicas. Vol. II (pp. 1007-1034). Murcia: Ediciones de la Universidad de Castilla.

Molina, R. (2000). Diccionario biográfico de Buenos Aires. Buenos Aires: Academia nacional de la Historia.

Moutoukias, Z. (2000). Gobierno y sociedad en el Tucumán y el Río de la Plata, 1550-1800. En E. Tandeter (Dir.), Nueva Historia Argentina. Tomo II. La sociedad colonial (pp. 13-54). Buenos Aires: Editorial Sudamericana.

Pérez Prendes y Muñoz de Arracó, J. (1989). La monarquía indiana y el estado de derecho. Valencia: Asociación Francisco López de Gómara.

Pico, J. (1992). Algunos españoles que vinieron a la Trinidad durante el siglo XVII. Genealogía. Revista del Instituto Argentino de Ciencias Genealógicas, 25, 735-803.

Pozzaglio, F. y Svriz Wucherer, P. (2016). Defendiendo una frontera. La ciudad de Corrientes, milicias e indios chaqueños, Siglos XVII-XVIII. Jahrbuch für Geschichte Lateinamerikas, 53, 6086.

Ribot, L. (2006). El arte de gobernar. Estudios sobre la España de los Austrias. Madrid: Alianza Editorial.

Saguier, E. (1989). La conducción de los caudales de oro y plata como mecanismo de corrupción. El caso del Situado asignado a Buenos Aires por las Cajas Reales de Potosí en el siglo XVIII. En Historia. Volumen 24 (pp. 287-317). Pontificia Universidad católica de Chile. Santiago de Chile..

Sanz Tapia, A. (2005). Leoneses en cargos de gobierno indianos a fines del siglo XVII. Estudios humanísticos, Historia, 4, 241-261.

Takeda, K. (2016). Las milicias guaraníes en las misiones jesuíticas del Río de la Plata: Un ejemplo de la transferencia organizativa y tácticas militares de España a su territorio de ultramar en la primera época moderna. Revista de Historia Social y de las Mentalidades, 20(2), 33-72.

Tarragó, G. (2016). Espacios en tensión, territorios en construcción. En D. Barriera, y R. Fradkin (Coord.), Gobierno, justicias y milicias La frontera entre Buenos Aires y Santa Fe (1720-1830) (pp. 41-69). La Plata: Universidad Nacional de La Plata.

Torre Revello, J. (1939). Los Gobernadores de Buenos Aires (1617-1777). En R. Levene (Dir.), Historia de la Nación Argentina (desde los orígenes hasta la organización definitiva en 1862), Vol. 
III (Pp. 327-370). Buenos Aires: Editorial Ateneo.

Valladares, R. (2006). Las dos guerras de Pernambuco. La armada del Conde da Torre y la crisis del Portugal hispánico (1638-1641). En J. Santos Pérez, y G. Cabral de Souza (Coord.), El desafío holandés al dominio ibérico en Brasil en el siglo XVII (pp. 33-66). Salamanca: Universidad de Salamanca.

Trujillo, O. (2009). Facciones, parentesco y poder: la élite de Buenos Aires y la rebelión de Portugal de 1640. En B. Yun Casalilla (Dir.), Las redes del Imperio. Elites sociales en la articulación de la monarquía hispánica, 1492-1714 (pp. 341- 358). Madrid: Marcial Pons.

Trujillo, O. (2014). Los Gobernadores de Buenos Aires a mediados del siglo XVII: mediación y conflicto en los confines de la Monarquía Hispánica. História, Histórias. Revista do Programa de Pós-Graduacao em História. 2(3), 92-108.

Zorraquín Becú, R. (1973). El oficio de gobernador en el derecho indiano. Revista de Historia del Derecho, 1, 251-286. 